\title{
Mechanical, Morphological, Thermal and Dynamic Study of Composites of Unsaturated Polyesters-Date Palm Leaf Fiber DPLF
}

\author{
Abir Berkouk $^{1 *}$, Ahmed Meghezzi ${ }^{1}$, Hamza Chelali $^{1}$, Mohamed Toufik Soltani² $^{2}$ \\ ${ }^{1}$ Laboratory of Applied Chemistry LCA, University of Biskra, BP 145 RP, Biskra 07000, Algeria \\ ${ }^{2}$ Laboratory of Physics of Photonics and Multifunctional Nanomaterials, University of Biskra, BP 145 RP, Biskra 07000 , \\ Algeria
}

Corresponding Author Email: abir.berkouk@univ-biskra.dz

https://doi.org/10.18280/rcma.310602

Received: 1 November 2021

Accepted: 10 December 2021

\section{Keywords:}

unsaturated polyester, date palm fiber, mechanical analysis, thermal analysis, morphological analysis, dynamic study

\begin{abstract}
In order to improve the properties of unsaturated polyesters, this study discusses the possibilities of developing a natural waste, date palm leaf fiber DPLF, produced in the northern Algerian Sahara, associated with the polymer matrix of a thermosetting polyester resin UP. For this purpose, composite plates containing virgin fiber at rates of 6 and $10 \%$ were treated with an alkaline solution of $6 \% \mathrm{NaOH}$ on the one hand, and a silane compound on the other. In this research, a mechanical study of strength and elongation at break was carried out. In addition, morphological behavior was followed by SEM scanning electron microscopy. ATG thermogravimetric analysis and energy flow were monitored by DSC differential scanning calorimetry. Also, a study of the water absorption capacity has been conducted. In addition, a dynamic mechanical analysis DMA was carried out. The findings of this study show that there is a favorable mechanical behavior for the composites containing the $6 \%$ and $10 \%$ DPLF fiber, with alkaline $\mathrm{NaOH}$ and Silane treatment. They also show that the chemical treatment with alkaline solution and silane gives composites certain thermal stability compared to those with untreated fiber. Findings also explore that the absorption of water by the various composites shows that the chemical treatment promotes some intermolecular associations with water. Findings also show that the storage modulus (E') increases when the composite contains $10 \%$ DPLF, treated and untreated, and the maximum value of the tangent moves towards the high temperature for the treated and untreated fiber composite.
\end{abstract}

\section{INTRODUCTION}

Unsaturated polyester (UP) is one of the polymers generally used in industry (automotive industry, aeronautics, electrical field, and others...etc.) [1, 2]. Due to its chemical structure as a thermosetting polymer. The natural date palm leaf fiber (DPLF) is considered a waste of nature in the regions of Northern Algeria (locality of Biskra). In order to enhance this natural waste, a series of polyester-fiber composites DPLF has been prepared.

This fiber is produced in the northern Algerian Sahara, due to the Saharan climate.

Nevertheless, it brings particular stability, which is the reason why it is associated as a natural reinforcement to polymers [3].

In the same logic of reflection, Ahmad et al. [4-6] carried out studies on composites based on epoxy resins and polyesters, looking for the influence of silica nanoparticles (sand) on the mechanical and thermal properties of the composite system. Also, Meftah et al. [7] explored the influence of alkaline treatment, and dune sand on the properties of DPLF date palm fiber reinforced with unsaturated polyester by forming hybrid composite systems. On the other hand, one can find in the literature the work effectuated by Alshammari et al. [8] based on the manufacture of epoxy resin composites have been carried out by among others mechanical analysis, morphological and physical properties, and water absorption, the fiber is varied like the date palm, palm tree trunk, fruit bunch stalk and leaf stalk.

In addition, Negawo et al. [9] have performed research on unsaturated polyester-based composites, looking for the influence of alkali-treated Ensete rod fibers on the mechanical, morphological, and dynamic properties of the composites. However, the mechanical tensile and flexural tests indicate that these properties were influenced by the alkali treatment, the flexural strength of the unsaturated polyester/Ensete fiber composites treated with $5.0 \% \mathrm{NaOH}(\sim 65 \mathrm{MPa})$ was improved by $14.5 \%$ compared to the untreated composites. Storage and loss modulus were highest for the alkali-treated $5.0 \mathrm{wt} \%$ Ensete fiber/UP composites compared to the untreated composites.

Similarly, Rozyanty et al. [10] studied the effect of water on the physical and mechanical properties of unsaturated polyester composites reinforced with Kenaf Bast fibers. The tensile strength of unsaturated polyester/Kenaf Bast fiber composites was increased with the loading of Kenaf Bast fibers. While water absorption was higher for UPE composites reinforced with mechanically retted kenaf fibers.

Furthermore, Salem et al. [11] explored the effect of Kenaf fiber surface change on the chemical structure and water 
absorption of unsaturated polyester composite. From the water absorption results, it was found that the increase of Kenaf fiber loading in the composite increased the water absorption capacity with the increase of stearic acid concentration. The water uptake decreased because stearic acid made the Kenaf fiber hydrophobic.

There are other studies developed on synthetic fibers as that of Bonnia et al. [12], who investigated the morphological and mechanical properties of unsaturated polyester (UP) reinforced with two types of fillers which are carbon black and Cloisite 30B nano-sized clay. From this research, the flexural strength of $\mathrm{CB} / \mathrm{UP}$ and $\mathrm{C} 30 \mathrm{~B} / \mathrm{UP}$ in $4 \mathrm{wt} \%$ was $76.59 \mathrm{MPa}$ and $90.85 \mathrm{MPa}$, and the addition of fillers improved the strength of unsaturated polyester composites, from SEM micrographs Cloisite 30B improved the performance of the composite.

Lee et al. [13] was on the effect of ice fiber surface modification on the properties of unsaturated polyester composites, which found that the flexural modulus and flexural strength of the $\delta$-Methacryloxypropyl trimethoxy silane (\&MPS)-treated unsaturated polyester/glass fiber composite were higher than those of the untreated composite, and SEM micrographs proved that the surface of the 8 -MPStreated glass fiber contains a lot of unsaturated polyester resin residue, and a small amount of resin adheres to the surface of the untreated glass fiber.

The main objective of this study is to improve the properties of unsaturated polyester through the effect of treated date palm leaf fiber, furthermore, this research was carried out with the aim of valorization of a natural waste, not exploited and harmful to the environment, which has been associated with a thermosetting polymer which is the unsaturated polyester (UP), and on account of its low economic cost.

This work focuses on the application of the date palm leaf fiber in the production of unsaturated polyester composites to verify the effects of the date palm leaf fiber without and with alkaline $\mathrm{NaOH}$ and silane treatment on the mechanical, morphological, thermal, water absorption, and dynamic behaviors of UP composites reinforced with DPLF.

Therefore, the Lay-up technique to manufacture the composites was considered, and for the characterization of the composites, a mechanical study, as well as a morphological one, were carried out. In addition, a thermal analysis was performed through thermogravimetric and differential calorimetric analysis. Then, a water absorption capacity study was concluded, and finally, dynamic mechanical analysis was performed.

\section{MATERIALS AND METHODS}

\subsection{Materials}

The polymer used in this study is unsaturated polyester (UP), and the catalyst is methyl ethyl-ketone peroxide (MEKP). They were equipped by LORN, is an Algerian-Chemical Company.

Table 1. Chemical constituents of leaf date palm fibers [14]

\begin{tabular}{cc}
\hline Cellulose & $40.21 \%$ \\
\hline Hemicelluloses & $12.8 \%$ \\
\hline Lignin & $32.2 \%$ \\
\hline Ash & $10.54 \%$ \\
\hline Extractive & $4.25 \%$ \\
\hline
\end{tabular}

In this study, date palm leaves were collected from local agricultural resources in the Biskra region of Algeria. They were washed, crushed, sieved, and stored in polyethylene bags. Table 1 presents the chemical constituents of leaf date palm fibers [14].

\subsection{Chemical treatments of date palm leaf fibers}

\subsubsection{Alkali treatment}

The date palm fiber leaves were soaked in a $6 \% \mathrm{NaOH}$ solution at $30^{\circ} \mathrm{C}$ for 24 hours. Then, they were washed with distilled water. They were neutralized up to $\mathrm{pH}=7$. Subsequently, they were dried at $80^{\circ} \mathrm{C}$ in a vacuum oven.

\subsubsection{Silane treatment}

The $\delta$-methacryloxypropyltrimethoxysilane $1 \%$ was dissolved in a mixture (methanol 90/water 10) (w/w). To adjust the $\mathrm{pH}$ to 4 , acetic acid was added under continuous stirring for $10 \mathrm{~min}$ at $30^{\circ} \mathrm{C}$ temperature.

The date palm fiber leaves were immersed in the prepared solution, under stirring for 3 hours at $40^{\circ} \mathrm{C}$. Then, they were filtered and dried in the open air for 24 hours at $80^{\circ} \mathrm{C}$ in a vacuum oven for 24 hours.

\subsection{Fabrication of UP composites}

The unsaturated polyester resin has been reinforced with treated and untreated DPLF fibers. The Lay-up technique was used to manufacture the composites. UP resin and treated and untreated DPLF were mixed at different percentages by weight. Then methyl ethyl ketone peroxide $1 \%$ by weight was added. Then, the mixture was poured into a stainless steel mold of size $160 \mathrm{~mm} \times 160 \mathrm{~mm} \times 2 \mathrm{~mm}$. Silicone was used in the mold as a release agent to facilitate the removal of the composites [15]

\subsection{Characterization}

\subsubsection{Mechanical characteristic}

Tensile testing of the composites was carried out in accordance with ASTM D638 using a Zwik/Roell Z050 type tensile testing machine at a tensile modulus speed of 1 $\mathrm{mm} / \mathrm{min}$ and a test speed of $100 \mathrm{~mm} / \mathrm{min}$.

\subsubsection{Morphological analysis}

The composites and virgin UP morphology were studied using a scanning electron microscope (SEM), type TESCAN VEGA 3.

\subsubsection{Thermal properties}

The composites and virgin UP thermograms were recorded using LABSYS evo (TGA/DSC) thermogravimetric analyzer and simultaneous differential scanning calorimeter from SETARAM instrumentation, from ambient temperature up to $500^{\circ} \mathrm{C}$, under an atmosphere (Ar), with a heating rate of $10^{\circ} \mathrm{C} / \mathrm{min}$.

\subsubsection{Water absorption}

Water absorption of UP/Date palm leaf fiber composites was measured every 48 hours for a total of 28 days. The percentage of water absorption was determined by the following Eq. (1) [16].

$$
\text { weight gain } \%=\left(\frac{\text { Wet weight }- \text { initial dry weight }}{\text { initial dry weight }}\right) \times 100
$$




\subsubsection{Dynamic analysis}

Dynamic study through the DMA technique was performed for our compositions by a TA instrument, DMA Q800 from ambient temperature up to $120^{\circ} \mathrm{C}$, with a heating rate of $5^{\circ} \mathrm{C} / \mathrm{min}$.

\section{RESULTS AND DISCUSION}

\subsection{Mechanical analysis of UP/DPLF composites}

The mechanical analysis (tensile strength and elongation at break) was done for composites containing DPLF 6 and $10 \%$ fiber without and with alkaline $\mathrm{NaOH} 6 \%$ and silane $1 \%$ treatment (Figures 1.a and 1.b).

Figures 1.a and 1.b show that there is a good mechanical behavior resulting in a good tensile strength and also a favorable elongation at break for the composites B5 (18.2 MPa; $2.2 \%)$, B6 (22 MPa; 2.2\%) and B7 (28.3 MPa; 2.6\%).

Good mechanical tensile strength for alkaline and silane treatment of the composites is noted, which is attributed to the good interracial adhesion between the matrix and the fiber presenting the crystalline character after chemical treatment, these findings are consistent with those of Negawo et al. [9]. An increase in the addition rate of the DPLF fiber to the UP polymer only decreases the mechanical properties of the composites [17], (see Figures 1.a and 1.b).

Sample B6 containing $6 \% \mathrm{NaOH}$ treated DPLF fiber showed high tensile strength and elongation at break of 22 $\mathrm{MPa}$ and 2.2\%, respectively. These results are in accordance with those of Meftah et al. [7], regarding tensile strength and flexural strength.
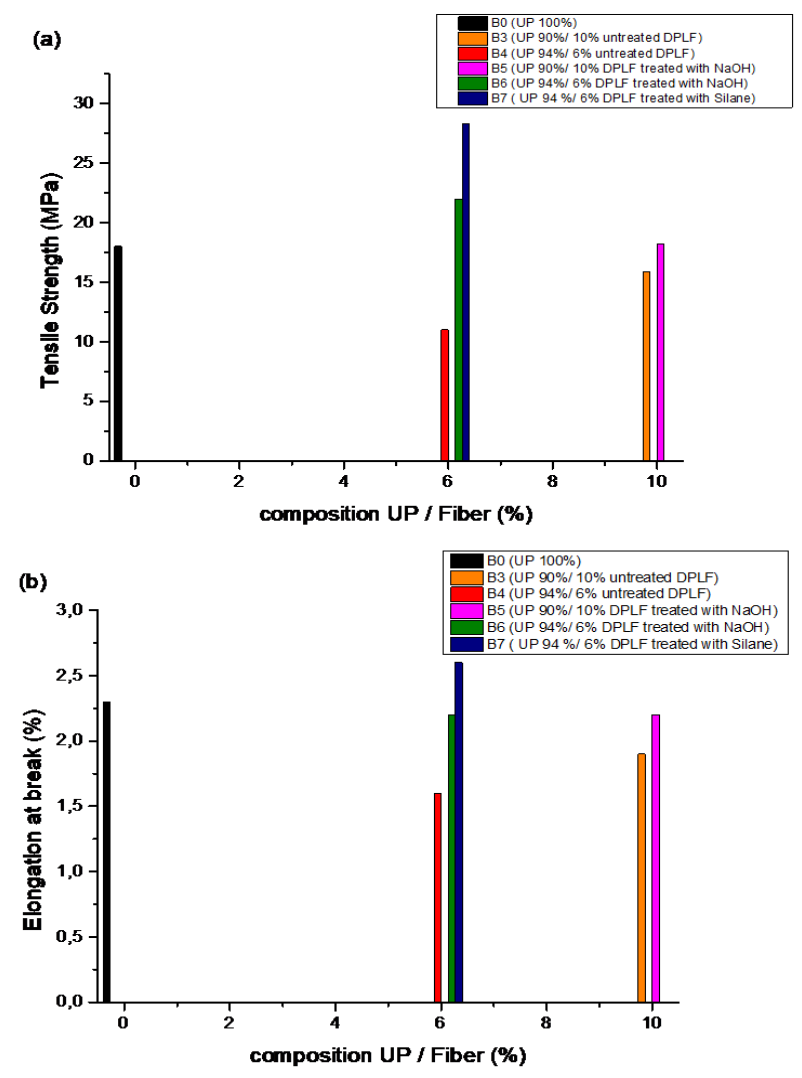

Figure 1. Evolution of the tensile strength (a), the elongation at break (b) of UP and composites with treated and untreated fibers
Our results confirm also that the tensile strength of our composites has improved by the alkaline treatment of date palm fibers, and this is in accordance with the findings of Rahman et al. [18] and Haameem et al. [19].

The strength and elongation at break of composites containing untreated DPLF (B3 and B4) are lower than that of virgin polyester (UP) B0, mainly due to the poor cohesion of the latter (fiber) with the organic matrix of the polymer Figures 1.a and 1.b.

\subsection{Morphological study of UP/DPLF composites}

In order to highlight the results previously found for the mechanical behavior, a morphological study of the composites was performed to promote the relationship at the level of the structure of the polymer matrix and the introduced fiber of the date palm leaf fiber DPLF treated and untreated with an alkaline solution of $\mathrm{NaOH}$. Figures 2.a, 2.b and 2.c show the micrographs of the composites B4, B3 and B6, respectively.
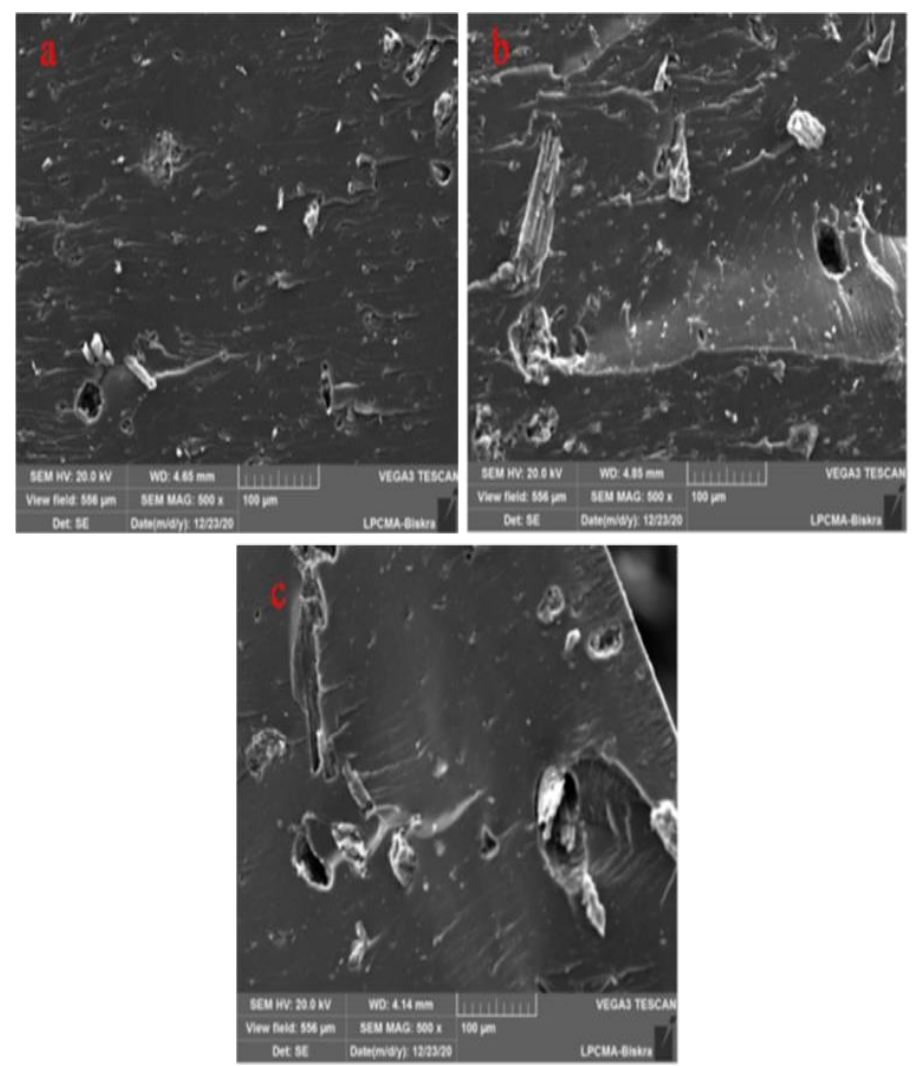

Figure 2. SEM micrographs of (a) UP/ 6\% DPLF (B4), (b) UP/ 10\% DPLF (B3), (c) UP / 6\% DPLF treated with $\mathrm{NaOH}$

Figures 2.a, 2.b illustrates the presence of agglomerates and gaps in the micrographs of the B4 and B3 composites. These agglomerates and gaps are the cause of poor interfacial cohesion between the polymer and the fiber, which is consistent with the results of Gharbi et al. [20]. With an increase in the rate of incorporated fiber, the image becomes more complicated (Figure 2.b), the polymer-fiber cohesion deteriorates, a non-homogeneous surface, which confirms the results obtained on the mechanical analysis (see 3.1 Mechanical analysis of UP/DPLF composites). Contrary to an acceptable rate of $\mathrm{NaOH}$-treated fiber (Figure 2.c), the B6 composite shows a clear image where the fiber is well dispersed on the polymer matrix, a good structure 
homogenization, this explains that the fiber treated with the alkaline solution gets rid of the hemicellulosic and lignin fractions and keeps the cellulosic fraction, which has the crystalline character which makes the adhesion easy (Figure 2.c), this further confirms the mechanical behavior of the B6 composite.

\subsection{Thermogravimetric study of UP/DPLF composites}

To evaluate the thermal stability, the thermogravimetric analysis (TGA) of UP/DPLF composites treated and untreated at 6 and $10 \%$ fiber content was studied, Figure 3 . The TGA curves of the composites are similar, two successive mass losses, the first relating to moisture elimination, the second one from $300^{\circ} \mathrm{C}$ relatives to the successive degradation of the composite. The results of this analysis showed that the chemical treatment of the fiber by sodium hydroxide and then incorporated into the polymer brings a certain thermal stability to the composite; this stability was evaluated by the mass of the mass residue around $450^{\circ} \mathrm{C}$.

As an example, composite B7 has a residual mass of $15,014 \mathrm{mg}(53.62 \%)$ which is stable compared to other composites. This is followed by composite B6 with a mass of $12,492 \mathrm{mg}$ (46.27\%), Table 2. These findings confirm the results of Gharbi et al. [20], and Arrakhiz et al. [21], thus the chemical treatment with alkaline solution or silane gives the composite certain thermal stability evaluated by the residual mass after thermal degradation. These results also confirm those of the mechanical behavior and morphological SEM analysis.

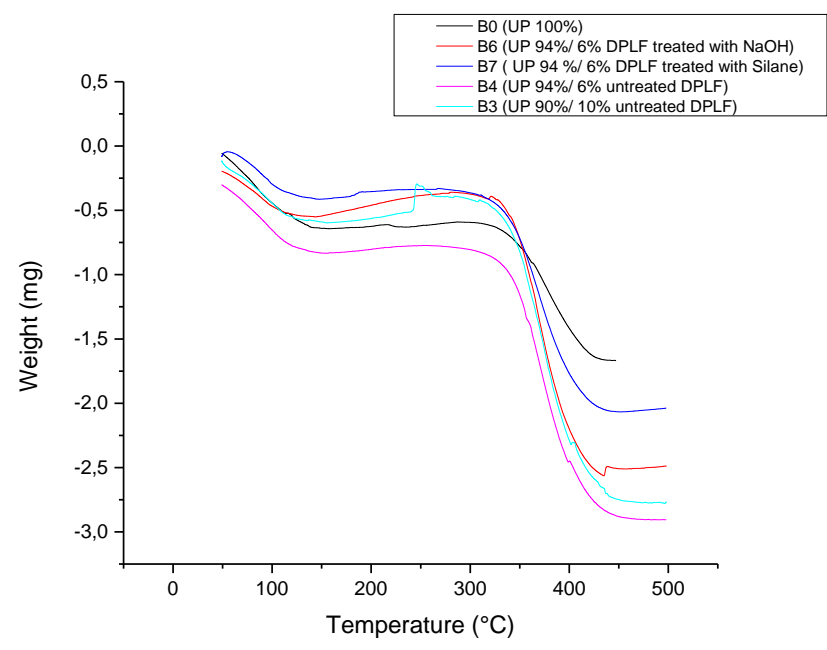

Figure 3. TG of different composites

Table 2. Residual masses at a temperature of $450^{\circ} \mathrm{C}$ of the various composites

\begin{tabular}{cccc}
\hline Composite & $\boldsymbol{m}_{\mathbf{0}}(\mathbf{m g})$ & $\begin{array}{c}\boldsymbol{m}_{\boldsymbol{r e s}}(\mathbf{m g}) \text { at } \\
\mathbf{4 5 0}^{\circ} \mathbf{C}\end{array}$ & $\frac{\boldsymbol{m}_{\text {res }}}{\boldsymbol{m}_{\mathbf{0}}} \boldsymbol{\%}$ \\
\hline B4 & 31 & 11.397 & 36.76 \\
B6 & 27 & 12.492 & 46.27 \\
B7 & 28 & 15.014 & 53.62 \\
\hline
\end{tabular}

\subsection{Differential scanning calorimeter study of UP/DPLF composites}

To validate the results of the ATG thermogravimetric analysis of the composites, a study using the DSC technique was carried out for these composites, Figure 4. On the DSC curves, the composites show a plateau of the glass transition temperature $\mathrm{Tg}$ in the range $50-100^{\circ} \mathrm{C}$. After this effect we note, as on the ATG curves, an endothermic effect of the humidity elimination around $100^{\circ} \mathrm{C}$; and the important effect of the successive degradation of the composite, endothermic effect which starts around $300^{\circ} \mathrm{C}$ and ends around $450^{\circ} \mathrm{C}$ (Figure 4), is the pyrolysis degradation which results in a split of the molecular chains leading to the destruction of the molecular network [22, 23].

Table 3 illustrates the temperature ranges of this thermal effect for the various composites, where it was noted that the maximum temperature of the effect is at $370^{\circ} \mathrm{C}$. Composite $\mathrm{B} 0$ has a final decomposition temperature $\mathrm{Tf}$ at $390^{\circ} \mathrm{C}$ (virgin UP), composites B4, B6, and B7, whose untreated fiber treated with $\mathrm{NaOH}$ and silane, respectively, show a significant increase in the final decomposition temperature of almost $30^{\circ} \mathrm{C}$ of the composite. This confirms the results found for the thermogravimetric analysis. The chemically treated fiber brings stability to the composite composition, it confers to the latter particular stability, since it acquires a change in its structure caused by the alkaline treatment and the action of silane.

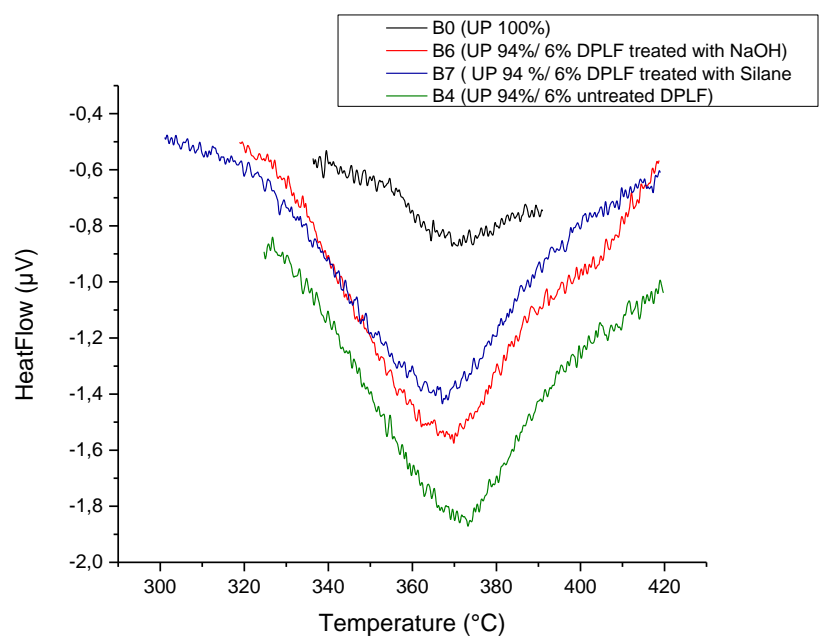

Figure 4. Endothermic peaks of different composites (from DSC)

Table 3. The decomposition temperature of the different composites

\begin{tabular}{cccc}
\hline Composite & $\boldsymbol{T}_{\boldsymbol{d}}\left({ }^{\circ} \mathbf{C}\right)$ & $\boldsymbol{T}_{\boldsymbol{m a x}}\left({ }^{\circ} \mathrm{C}\right)$ & $\boldsymbol{T}_{\boldsymbol{f}}\left({ }^{\circ} \mathrm{C}\right)$ \\
\hline B0 & 347.37 & 370.35 & 390.35 \\
B4 & 324.71 & 371.63 & 419.76 \\
B6 & 318.85 & 369.37 & 419.76 \\
B7 & 301.12 & 366.37 & 419.76 \\
\hline
\end{tabular}

\subsection{Water absorption of UP/DPLF composites}

The immersion study of our composites was conducted in a function of time. The results are given in Figure 5.

It can be seen that the chemically treated fiber acquires a decrease in hydrophilicity and this necessarily contributes to the decrease in the sensitivity of the composite to water.

The chemical treatment favors certain intermolecular associations with water which makes the composite sensitive to water, (See Figure 5), under the results of Siala et al. [24]. 


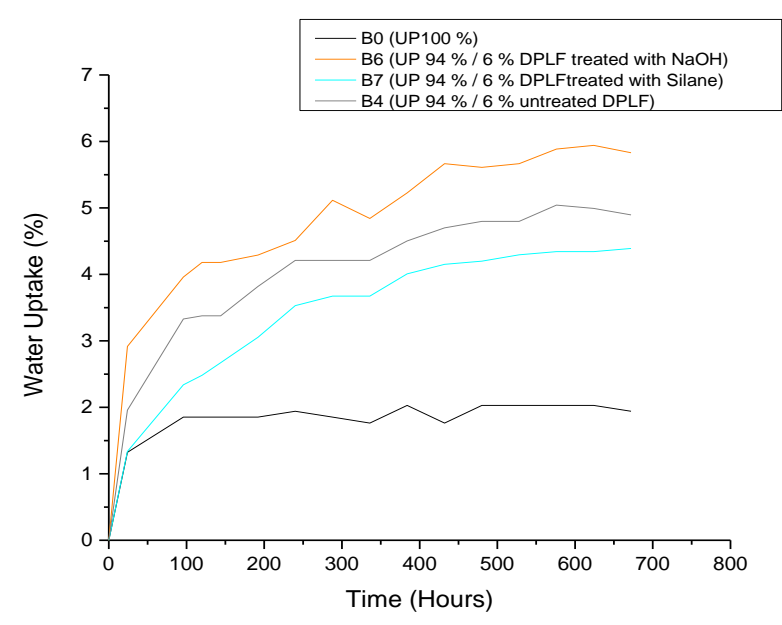

Figure 5. Water absorption of composites with treated and untreated fibers and virgin UP

\subsection{Dynamic study of UP/DPLF composites}

A dynamic study through the DMA technique was performed for our compositions. The curves for loss modulus, storage modulus, and Tan Delta $\delta$ were obtained on a TA instrument, DMA Q800. In addition, a series of samples B0, B3, B4, B5, and B6 were conducted. When the composites B0, $\mathrm{B} 3$, and $\mathrm{B} 5$ were analyzed; it was found that the storage modulus ( $\left.E^{\prime}\right)$ increases when the composite contains $10 \%$ DPLF, treated and untreated, e.g. at $70^{\circ} \mathrm{C}, \mathrm{B} 0\left(\mathrm{E}^{\prime}=380.17\right.$ $\mathrm{MPa}), \mathrm{B} 3\left(\mathrm{E}^{\prime}=1264.46 \mathrm{MPa}\right), \mathrm{B} 5\left(\mathrm{E}^{\prime}=1365.70 \mathrm{MPa}\right)$, (see Figure 6). These results are in agreement with the water absorption data, where an increase in water absorption capacity is seen for the chemically treated fiber composite. Regarding the loss modulus (E"), it is seen that the virgin polymer UP, the loss modulus starts at the temperature of $54.69^{\circ} \mathrm{C}$; $\mathrm{E} "=354.33 \mathrm{MPa}$, in contrast, the losses for the composite $\mathrm{B} 3$ and $\mathrm{B} 5$ are respectively $\mathrm{E}^{\prime \prime}=245.82 \mathrm{MPa}$; $\mathrm{T}=74.31^{\circ} \mathrm{C}$ and $\mathrm{E}^{\prime \prime}=209.23 \mathrm{MPa} ; \mathrm{T}=79.65^{\circ} \mathrm{C}$, which reflects the undeniable effect of fiber on the composite properties, Figure 7. Concerning the Tan Delta $\delta$, it is seen that the maximum value of the tangent moves towards the high temperature for the treated and untreated fiber composite, for $\mathrm{B} 0$ (Tan $\delta=0.91$ at $\mathrm{T}=82.18^{\circ} \mathrm{C}$ ), for $\mathrm{B} 3$ (Tan $\delta=0.60$ at $\left.\mathrm{T}=93.90^{\circ} \mathrm{C}\right)$, for $\mathrm{B} 5\left(\tan \delta=0.65\right.$ at $\left.\mathrm{T}=101.29^{\circ} \mathrm{C}\right)$ Figure 8.

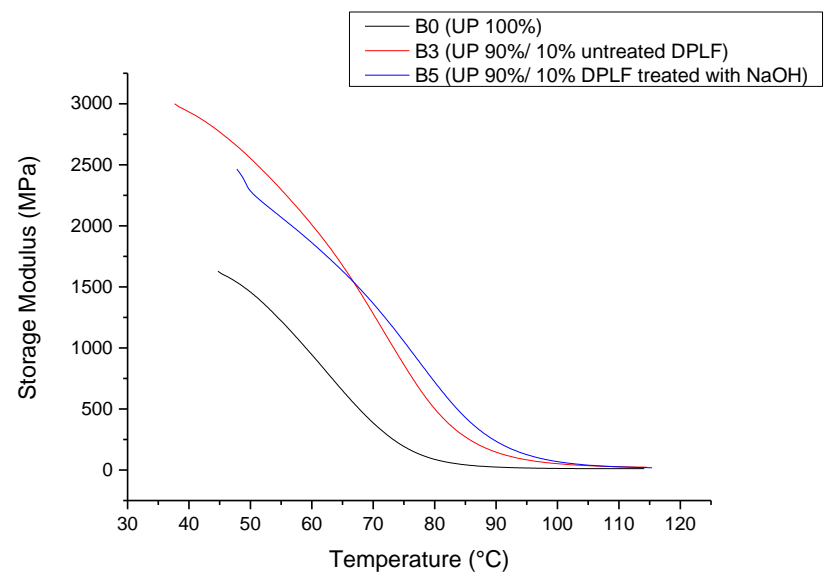

Figure 6. Storage Modulus of composites

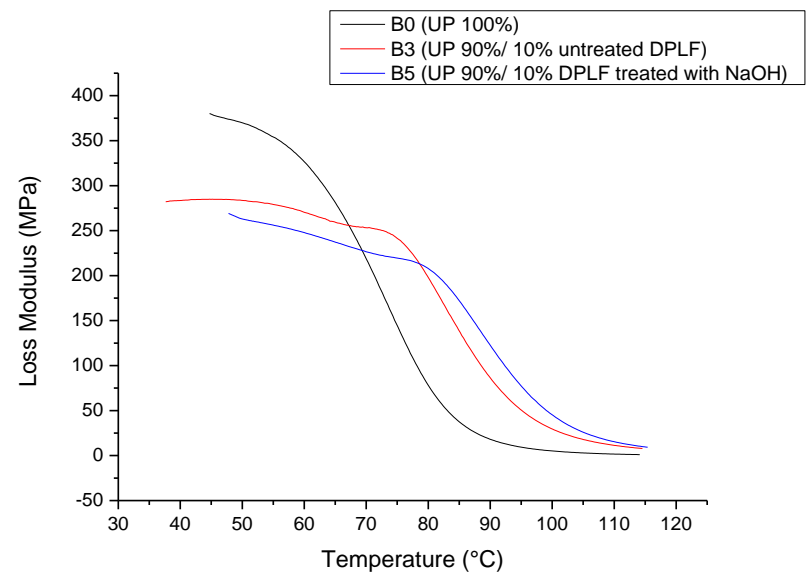

Figure 7. Loss Modulus of composites

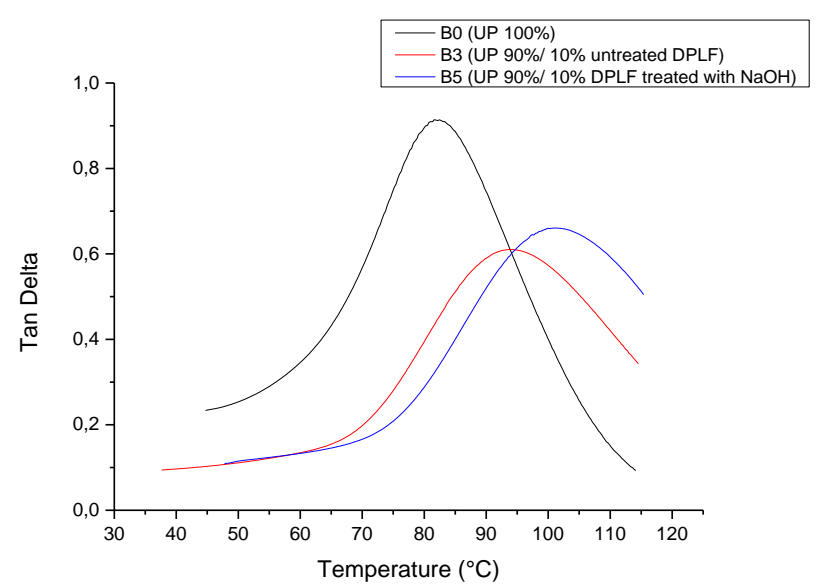

Figure 8. Tan Delta of composites

\section{CONCLUSION}

This paper highlights date palm leaf fiber with and without chemical treatment in composites based on unsaturated polyester resin. On the other hand, the study focuses on the effects of the Silane and alkaline treatment on the mechanical, morphological and thermal properties as well as on the possibility of water absorption also the dynamic properties.

Findings of this research show favorable mechanical behavior for composites containing $6 \%$ and $10 \%$ DPLF fiber, with alkaline $\mathrm{NaOH}$ and Silane treatment. This is confirmed through the morphological study by the mechanical behavior of these composites. Our findings show that the chemical treatment with the alkaline solution and the silane confers to the composites convinced thermal stability compared to those whose fiber is untreated, thus allowing confirmation of the mechanical behavior and the SEM morphological analysis of these composites. The study of water absorption by the various composites shows that the chemical treatment favors some intermolecular associations with water, which makes the composite sensitive to the latter. The study of dynamic mechanical analysis shows that storage modulus increases when the composite contains $10 \%$ DPLF, treated and untreated, these results are in accord with the water absorption data. The loss modulus shows the effect of fiber on the composite properties. Also, the maximum value of the tan Delta $\delta$ moves to the high temperature for the treated and untreated fiber composite. 
Further complimentary research is suggested by this study, as a structural study on infrared spectroscopy for fiber and composite (structural characterization) to evaluate the fiber crystalline character and its contribution to the composite, as well as this study, invites to study the X-ray diffraction (XRD). In addition, the prospects of this research focus on the realization of the same experimental protocol applied above, replacing the unsaturated polyester with epoxy resin (thermosetting polymer of the same rank) and associating a natural fiber hybrid form, namely DPLF-Carbon nanofiber, DPLF- Olive leaf and DPLF-Date nut for the preparation of new composites, so it can be seen in a possible further comparative study between the two composites (UP and epoxy resin and fiber).

\section{ACKNOWLEDGMENT}

The authors would like to thank Amina LOUCIF, head of the plastic analysis laboratory of the cable company of Biskra, Algeria, for carrying out the mechanical tests of this study.

\section{REFERENCES}

[1] Lin, Y., Jiang, S., Hu, Y., Chen, G., Shi, X., Peng, X. (2018). Hybrids of aluminum hypophosphite and ammonium polyphosphate: Highly effective flame retardant system for unsaturated polyester resin. Polymer Composites, 39(5): 1763-1770. https://doi.org/10.1002/pc.24128

[2] Dai, K., Song, L., Hu, Y. (2013). Study of the flame retardancy and thermal properties of unsaturated polyester resin via incorporation of a reactive cyclic phosphorus-containing monomer. High Performance Polymers, 25(8): 938-946. https://doi.org/10.1177\%2F095400831349076

[3] Maou, S., Meghezzi, A., Nebbache, N., Meftah, Y. (2019). Mechanical, morphological, and thermal properties of poly (vinyl chloride)/low-density polyethylene composites filled with date palm leaf fiber. Journal of Vinyl and Additive Technology, 25(s2): E88-E93. https://doi.org/10.1002/vnl.21687

[4] Ahmad, T., Mamat, O., Ahmad, R. (2013). Studying the effects of adding silica sand nanoparticles on epoxy based composites. Journal of Nanoparticles, 2013: 1-5. https://doi.org/10.1155/2013/603069

[5] Ahmad, T., Ahmad, R., Kamran, M., Wahjoedi, B., Shakoor, I., Hussain, F., Riaz, F., Jamil, Z., Isaac, S., Ashraf, Q. (2015). Effect of Thal silica sand nanoparticles and glass fiber reinforcements on epoxybased hybrid composite. Iranian Polymer Journal, 24(1): 21-27. https://doi.org/10.1007/s13726-014-0296-X

[6] Ahmad, T., Rasa, S.S., Aleem, E., Kamran, M., Manzoor, U., Makhdoom, A., Ahmad, R., Mukhtar, S. (2017). Improvement in mechanical and thermal properties of unsaturated polyester-based hybrid composites. Iranian Polymer Journal, 26(4): 305-311. https://doi.org/10.1007/s13726-017-0520-6

[7] Meftah, Y., Tayefi, M., Fellouh, F., Chouieur, H., Maou, S., Meghezzi, A. (2020). Influence of alkali treatment and dune sand content on the properties of date palm fiber reinforced unsaturated polyester hybrid composites. Revue des Composites et des Matériaux Avancés-Journal of Composite and Advanced Materials, 30(3-4): 161-167. https://doi.org/10.18280/rcma.303-406

[8] Alshammari, B.A., Saba, N., Alotaibi, M.D., Alotibi, M.F., Jawaid, M., Alothman, O.Y. (2019). Evaluation of mechanical, physical, and morphological properties of epoxy composites reinforced with different date palm fillers. $\quad$ Materials, 2145. https://doi.org/10.3390/ma12132145

[9] Negawo, T.A., Polat, Y., Buyuknalcaci, F.N., Kilic, A., Saba, N., Jawaid, M. (2019). Mechanical, morphological, structural and dynamic mechanical properties of alkali treated Ensete stem fibers reinforced unsaturated polyester composites. Composite Structures, 207: 589-597. https://doi.org/10.1016/j.compstruct.2018.09.043

[10] Rozyanty, A.R., Zhafer, S.F., Shayfull, Z., Nainggolan, I., Musa, L., Zheing, L.T. (2021). Effect of water and mechanical retting process on mechanical and physical properties of kenaf bast fiber reinforced unsaturated polyester composites. Composite Structures, 257: 113384 https://doi.org/10.1016/j.compstruct.2020.113384

[11] Salem, I.A.S., Rozyanty, A.R., Betar, B.O., Adam, T., Mohammed, M., Mohammed, A.M. (2017). Study of the effect of surface treatment of kenaf fiber on chemical structure and water absorption of kenaf filled unsaturated polyester composite. Journal of Physics: Conference Series, 908(1): 012001. https://doi.org/10.1088/17426596/908/1/012001

[12] Bonnia, N.N., Redzuan, A.A., Shuhaimeen, N.S. (2016). Mechanical and morphological properties of nano filler polyester composites. MATEC Web of Conferences. 39: 01008. https://doi.org/10.1051/matecconf/20163901008

[13] Lee, G.W., Lee, N.J., Jang, J., Lee, K.J., Nam, J.D. (2002). Effects of surface modification on the resintransfer moulding (RTM) of glass-fibre/unsaturatedpolyester composites. Composites Science and Technology, 62(1): 9-16. https://doi.org/10.1016/S02663538(01)00091-4

[14] Mirmehdi, S.M., Zeinaly, F., Dabbagh, F. (2014). Date palm wood flour as filler of linear low-density polyethylene. Composites Part B: Engineering, 56: 137-141.

https://doi.org/10.1016/j.compositesb.2013.08.008

[15] Saba, N., Alothman, O.Y., Almutairi, Z., Jawaid, M., Ghori, W. (2019). Date palm reinforced epoxy composites: tensile, impact and morphological properties. Journal of Materials Research and Technology, 8(5): 3959-3969. https://doi.org/10.1016/j.jmrt.2019.07.004

[16] Ramesh, M., Deepa, C., Selvan, M.T., Rajeshkumar, L., Balaji, D., Bhuvaneswari, V. (2021). Mechanical and water absorption properties of Calotropisgigantea plant fibers reinforced polymer composites. Materials Today: Proceedings, 46(9): 3367-3372. https://doi.org/10.1016/j.matpr.2020.11.480

[17] Shanmugasundaram, N., Rajendran, I., Ramkumar, T. (2018). Static, dynamic mechanical and thermal properties of untreated and alkali treated mulberry fiber reinforced polyester composites. Polymer Composites, 39(S3): E1908-E1919. https://doi.org/10.1002/pc.24890

[18] Rahman, M.R., Hamdan, S., Hasan, M., Baini, R., Salleh, A.A. (2015). Physical, mechanical, and thermal properties of wood flour reinforced maleic anhydride grafted unsaturated polyester (UP) biocomposites. Bio 
Resources,

10(3):

http://doi.org/10.15376/biores.10.3.4557-4568

[19] Haameem, JA.M., Majid, A., Afendi, M., Marzuki, H.F.A., Fahmi, I., Gibson, A.G. (2016). Mechanical properties of Napier grass fibre/polyester composites. Composite Structures, 136: 1-10. http://doi.org/10.1016/j.compstruct.2015.09.051

[20] Gharbi, A., Bel-Hassen, R., Boufi, S. (2014). Composite materials from unsaturated polyester resin and olive nuts residue: the effect of silane treatment. Industrial Crops and Products, 62: 491-498 https://doi.org/10.1016/j.indcrop.2014.09.012

[21] Arrakhiz, F.Z., Malha, M., Bouhfid, R., Benmoussa, K. Qaiss, A. (2013). Tensile, flexural and torsional properties of chemically treated alfa, coir and bagasse reinforced polypropylene. Composites Part B: Engineering, 47: 35-41. https://doi.org/10.1016/j.compositesb.2012.10.046

[22] Hossain, M.K., Karim, M.R., Chowdhury, M.R., Imam, M.A., Hosur, M., Jeelani, S., Farag., R. (2014). Comparative mechanical and thermal study of chemically treated and untreated single sugarcane fiber bundle. Industrial Crops and Products, 58: 78-90. https://doi.org/10.1016/j.indcrop.2014.04.002

[23] Arrieta, J.S., Richaud, E., Fayolle, B., Nizeyimana, F.
(2016). Thermal oxidation of vinyl ester and unsaturated polyester resins. Polymer Degradation and Stability, 129: 142-155. https://doi.org/10.1016/j.polymdegradstab.2016.04.003

[24] Siala, A., Khay, S.E.E., Neji, J. (2017). Contribution of the addition of reclaimed asphalt pavement and dune sand on the hot-mix asphalt performances. Revue des Composites et des MatériauxAvancés, 27(1-2): 191-208. https://doi.org/10.3166/rcma.2017.00014

\section{NOMENCLATURE}

B0 unsaturated polyester $100 \%$

B3 unsaturated polyester $90 \% / 10 \%$ untreated date palm leaf fiber

B4 unsaturated polyester $94 \%$ / $6 \%$ untreated date palm leaf fiber

B5 unsaturated polyester 90\% / 10\% date palm leaf fiber treated with $\mathrm{NaOH}$

B6 unsaturated polyester 94\% / 6\% date palm leaf fiber treated with $\mathrm{NaOH}$

B7 unsaturated polyester $94 \%$ / $6 \%$ date palm leaf fiber treated with Silane 